\title{
El periodo formativo de un intelectual: Milciades Peña y el trotskismo en las décadas de 1940-1950
}

\author{
Hernán Camarero
}

(CONICET - UBA)

Milcíades Peña presenta una singularidad en el campo intelectual. Fue el forjador de la más original, desmitificadora y punzante interpretación marxista de la historia argentina, en particular de sus clases dominantes, en base a un relato y un método de análisis al que se le fue reconociendo lucidez durante la segunda mitad del siglo XX y cuya vigencia se comprueba aún hoy día. Un pensador crítico y autodidacta, pero no "libre", formado en la escuela del compromiso político y militante del trotskismo; que no poseyó siquiera un título secundario, pero cuyas ideas son discutidas en la universidad (y a veces reapropiadas sin citar debidamente su origen); y que elaboró toda su obra con una increíble precocidad, antes de morir muy tempranamente, al suicidarse en diciembre de 1965, cuando apenas tenía 32 años.

¿Cuáles fueron los aspectos que han sido más explorados y destacados de Peña? Pueden resumirse en tres. Por un lado, sus aportes acerca de las características socio-económicas del capitalismo argentino, "atrasado y semicolonial", donde supo descubrir los peculiares rasgos adquiridos por la burguesía, la estructura agraria y la industrialización. Por el otro, su proyecto de montar una gran obra historiográfica con cierta vocación integral, elaborada entre 1955-1957, la cual apuntaba al reconocimiento de los grandes trazos del pasado nacional y a la polémica con las interpretaciones existentes; con excepción de algunos pasajes, ésta fue publicada póstumamente y pudo reeditarse sólo recientemente como obra única y bajo el título concebido por su autor: Historia del pueblo argentino (2012). Por último, su rol de fundador y principal artífice de una revista teórica distintiva de la izquierda intelectual sesentista: Fichas de investigación económica y social (1964-1965).

En líneas generales, el foco de análisis fue puesto en los últimos siete u ocho años de vida de Peña, cuando estaba en proceso de desvinculación con su corriente política, devenía un intelectual marxista independiente 
y comenzaban a conocerse la mayor parte de sus realizaciones teóricas. Mucho menos recorrido por el estudio ha sido el ciclo previo, el de su formación y militancia en la izquierda revolucionaria, la cual abarcó el tercio final de la década del 40 y la casi totalidad de los años 50 . El objetivo de las páginas que siguen pretende abordar, precisamente, esta problemática. En ellas no ofrecemos una reconstrucción global de la figura de Peña, ni una valoración integral de su obra, ni una consideración específica, teórica e historiográfica, de su trabajo más consagrado, Historia del pueblo argentino. Nos parece que éstas han sido cuestiones muy atendidas. ${ }^{1}$ En cambio, a partir del relevamiento de una serie de fuentes primarias, lo que exploraremos aqui son otros asuntos, escasamente tramitados: el modo en que Peña se vinculó e insertó en una de las tendencias del trotskismo; las características teóricas, políticas, programáticas y organizativas de dicha corriente; y la incidencia que esta experiencia militante tuvo en la formación intelectual de Peña. El planteo que recorre este artículo es que, si bien la producción teórica de Peña luego fue cobrando una extraordinaria lucidez, originalidad y autonomía creativa, apenas puede comprenderse sin sus contextos militantes previos. Esto es lo que nos proponemos reconstruir. En nuestro relato queremos enhebrar la doble trama de una historia del trotskismo y de Peña, del partido y del intelectual, reflexionando sobre las complejas relaciones que se establecieron entre ambos.

\section{El ingreso de Milciades Peña al trotskismo}

Peña había nacido en mayo de 1933 en la ciudad de La Plata. Su infancia nos remite a un niño criado en el ámbito de la clase media urbana por sus tíos, un matrimonio mayor que lo adoptó ante la imposibilidad que presentaba su madre para atenderlo, quien padecia de graves problemas nerviosos. Incluso, la propia existencia de sus padres y hermanos le fue desconocida al joven hasta sus once años, hecho que le habría provocado "una crisis de identidad" que lo marcaría para siempre (Tarcus, 1996: 109). Su temprana pasión por la literatura quedó favorecida por el hecho de que su tío se desempeñaba como empleado en la biblioteca de la Universidad Nacional de La Plata, lo que proporcionó el ámbito necesario para que pudiera aproximarse, de manera muy prematura, a ciertos campos de la literatura, la historia, la política y la filosofia. El camino hacia la política se presentó también apresuradamente cuando, hacia mediados de 1946, ingresó a la juven-

1. El trabajo más significativo sobre la vida y obra de Peña es Tarcus (1996). Sobre Historia del pueblo argentino y las concepciones historiográficas de Peña, cfr.: Tarcus, 1996: 161-304; Acha, 2009: 249-284. 
tud del Partido Socialista (PS), en pleno enfrentamiento con el naciente peronismo. Sin embargo, un año después abandonaba ese partido, para incorporarse al trotskismo, una corriente que venía despuntando en la escena nacional desde hacía unos años. ${ }^{2}$

Tras una década de dispersión, divisiones, persecución política, hostilidad del estalinismo vernáculo y ocasionales intervenciones en el campo sindical y la bohemia intelectual, hacia 1941 los trotskistas habían logrado agrupar a casi todas sus vertientes bajo una sola sigla: el PORS (Partido Obrero de la Revolución Socialista). Pero esta fuerza no fue duradera y poco después estalló en diversos sectores. De allí emergieron el Grupo Cuarta Internacional (GCI, orientado por Jorge Posadas), la Unión Obrera Revolucionaria (UOR, de Miguel Posse), el grupo Octubre de Jorge Abelardo Ramos y el Grupo Obrero Marxista (GOM). Fue en esta última y pequeña organización donde comenzó a militar Peña. El GOM había sido fundado hacia 1943 bajo impulso de Hugo Miguel Bressano (1924-1987), quien luego de un breve paso por el PORS recaló en la Liga Obrera Revolucionaria dirigida por Liborio Justo. Fue este último quien lo apodó con el nombre de Nahuel Moreno, con el que se lo conoceria hasta el final de su vida. Moreno era un joven de clase media acomodada, proveniente de un pueblo ganadero bonaerense, que había sido enviado a la Capital para realizar sus estudios primarios y secundarios. Con inclinaciones culturales hacia la literatura clásica, la filosofia de Kant y Hegel y la crítica teatral, se había introducido en el ambiente político-intelectual de la izquierda desde 1939. Pronto, un puesto de trabajo en el Ministerio de Hacienda y una carrera universitaria quedaron abandonados por sus actividades al frente del GOM, a las cuales terminó dedicando todo su tiempo.

El grupo inicialmente reclutó voluntades entre un puñado de jóvenes obreros judíos de Villa Crespo. Si el movimiento cuartainternacionalista argentino se hallaba aquejado por la disgregación y la desorientación, evaluaba el GOM, ello respondía no exclusivamente a desvarios de carácter programático, sino a su carácter social, esencialmente pequeñoburgués y alejado de los trabajadores. Esto quedó plasmado en un documento escrito por Moreno en 1943, El partido, donde se estableció como objetivo básico la vinculación directa con el proletariado en lucha. En 1944-1945 el GOM se encontró apoyando diversos conflictos obreros y la mayoría de sus militantes se fue a vivir a un pobre conventillo del barrio de Villa Pobladora, en Avellaneda, para profundizar su contacto con el proletariado industrial de mayor nivel de concentración y explo-

2. Para una reconstrucción histórica del trotskismo durante las décadas de 19301940, cfr.: Alexander, 1973: 45-68; González, 1995; Tarcus, 1996; Coggiola, 2006; Galasso, 2007; Rojo, 2012. 
tación, donde ganó la adhesión de algunos activistas en los gremios de la carne, textil y metalúrgico. Desde octubre de 1946 el GOM editó un precario órgano de prensa: Frente Proletario. Un rasgo "obrerista" afectó al grupo: reivindicaba la necesidad de una elaboración teórica marxista, pero rechazaba todo trabajo específico o privilegiado con intelectuales y estudiantes. Si captaba para sus filas a algunos de ellos, era para enviarlos sin mediaciones a estructurarse entre los trabajadores (Veiga, 2006: 66).

¿Qué caracterización hizo el GOM acerca del peronismo en sus primeros años? A la movilización del 17 de octubre de 1945 la definió como una "lucha de camarillas", en la que "el proletariado atrasado salió a defender el orden burgués contra la propia burguesía". El GOM subestimó los componentes nacionalistas del nuevo proceso y sus políticas de concesiones al movimiento obrero. Ya había entendido el golpe del 4 de junio de 1943 como una iniciativa en defensa de la vieja estructura del país ligada al imperialismo inglés. ${ }^{3}$ Luego, a Perón lo entendió como una expresión de los intereses del sector más fuerte de la burguesía argentina, los terratenientes, los cuales habrian ofrecido cierta resistencia al avance de la influencia norteamericana que afectaba a la economía en su conjunto, tradicionalmente ligada al capital británico. "Los hechos desde hace tiempo nos vienen demostrando cómo el gobierno no es más que un agente político de la City de Londres", sostenía el grupo. ${ }^{4}$ Definía al peronismo en un contexto de "reflujo" de la clase obrera (en buena medida por el papel de sus direcciones reformistas), la cual fue utilizada por aquel, en un contexto de prosperidad económica. Según esta visión, los trabajadores sirvieron al plan demagógico del gobierno y fueron desviados de sus objetivos históricos de clase. Y la estatización de los sindicatos tuvo un contenido burgués en función de disciplinar a la clase obrera. A pesar de denunciar el carácter totalitario y reaccionario de la burocracia sindical y del control estatal, se dispuso a actuar en los nuevos y masivos sindicatos. Tiempo después, la corriente acabó definiendo al peronismo como un "bonapartismo sui géneris". ${ }^{5}$

Entre 1945 y 1946, el GOM tuvo oportunidad para el desarrollo de una experiencia "entrista" dentro de la juventud del PS. No era parte

3. Comunicado sobre el golpe del 4 de junio de 1943, Boletín de Discusión del GOM, $\mathrm{N}^{\circ} 1$, julio 1944.

4. "Perón y el convenio con Inglaterra", Frente Proletario, año I, No 1 , octubre de 1946, p. 5. Ver, también: "Las declaraciones de Miranda", Frente Proletario, año II, n 19, 12 de agosto de 1948, p. 1.

5. La continuidad de las caracterizaciones criticas hacia el peronismo puede verse expresada y sintetizada en N. Moreno, "El Grupo Cuarta Internacional (GCI), agente ideológico del peronismo en el movimiento obrero", Revolución Permanente, año III, $\mathrm{N}^{\circ} 7-8$, noviembre de 1951. 
de una orientación global, tal como preconizó Trotsky en la década del 30 , como vía para ganar la adhesión de sus militantes obreros y de izquierda (lo cual, en algunos países, tuvo cierta eficacia). En Avellaneda fueron influenciados unos jóvenes socialistas de Bahía Blanca, Ángel A. Bengochea y Horacio Lagar, quienes, vueltos a su lugar de origen, lograron acercar a otros, y desde este núcleo pudieron ejercer un papel dirigente en la juventud partidaria de la ciudad sureña. Al mismo tiempo, Bengochea y Lagar, estudiantes de Historia en la Universidad Nacional de La Plata, trabaron relación con afiliados de la Juventud Socialista de esta ciudad, quienes fueron captados para las filas del GOM. Milciades Peña pertenecía a ese grupo, junto a José D. Speroni, Oscar Valdovinos y el futuro historiador Alberto J. Plá, entre otros. La documentación interna del GOM permite establecer el momento del ingreso de Peña al mismo, indicando que en octubre de 1947 era uno de sus 50 integrantes orgánicos en una de las 11 células partidarias, la de la regional platense. ${ }^{6}$ Milcíades, de escasísima edad (se hallaba cursando su bachillerato en el Colegio Nacional de esa ciudad, que luego abandonó), fue uno de los pocos de estos nuevos militantes que no ingresó a trabajar a una fábrica para devenir activista sindical, quedando más bien ocupado de tareas de tipo intelectual.

En un inicio, hubo un inevitable carácter asimétrico y discipular en el estrecho vínculo entre Moreno y Peña. Incidía la diferencia generacional: el primero tenía en ese entonces veintitrés años; el segundo, catorce. Pero también en acumulación de experiencia y capital político. El fundador del GOM llevaba sus últimos siete años militando en el trotskismo, trabando relación con sus principales protagonistas, desplegando escritos teórico-políticos y dictando cursos de iniciación marxistas, que operaban como orientación de una corriente con una incidencia muy localizada en algunas luchas del movimiento obrero. En abril de 1948 había podido viajar a París durante un mes, para asistir al II Congreso de la Cuarta Internacional, en donde una nueva camada de cuadros políticos (el griego Michel Raptis "Pablo", el belga Ernest Mandel, el francés Pierre Frank, el italiano Livio Maitán y otros) procuraba reconstruir la organización fundada por Trotsky diez años antes. Para Peña, la incorporación al GOM significó la apertura de un mundo nuevo: el de la militancia revolucionaria en una tradición ideológico-política cargada de fuertes rasgos identitarios. Dentro de ese ámbito pequeño y marginal, como expresión de una suerte de rito de pasaje, pasó a ser llamado Hermes Radio, el apodo con el que transcurrió toda su experiencia de compromiso con el trotskismo hasta fines de 1959. Cuando a fines de diciembre de 1948 la agrupación, que ya se había expandido

6. Informes del Buró Político del GOM, 1947. 
a casi el centenar de miembros, realizó un congreso, en el cual cambió su nombre por el de Partido Obrero Revolucionario (POR), Radio fue uno de sus 21 delegados e incluso fue elegido para integrar su Comité Central (CC). Sus labores continuaron siendo las de brindar ayuda a Moreno en la búsqueda de bibliografia, fuentes y datos estadísticos, y en tareas de colaboración en el periódico Frente Proletario.

\section{Las elaboraciones teóricas del GOM-POR}

El moderado crecimiento experimentado en las fuerzas del GOM-POR, no obstante, pareció haber llegado a un límite hacia 1947-1948. Muchos años después, el líder de esa corriente, en una entrevista con el escritor Juan José Sebreli, señalaba que el "curso totalitario" del peronismo tras su acceso al poder habría sido un factor decisivo del retroceso y relativa pasividad de la clase obrera, hasta 1952 aproximadamente, lo cual habria mermado las posibilidades de expansión de la pequeña organización. Este proceso, sin embargo, coexistió con un particular interés por el estudio y la elaboración conceptual del colectivo: "Nuestro grupo se debilitaba, había pocas luchas y huelgas obreras. Pero entre 1947-1949, contradictoriamente (...) es cuando mejor fructifican los trabajos teóricos". ${ }^{7}$

Esto implicó un reacomodamiento en las tareas de Moreno y en la colaboración que Peña comenzó a prestarle. El primero se trasladó desde Villa Pobladora a una modesta pensión céntrica capitalina, comenzando a internarse en una investigación, amateur y ensayística, de la estructura y dinámica económico-social argentina, con el fin de readecuar programáticamente al grupo. En la mencionada entrevista con Sebreli, sostenia: "De esa época vienen, creo yo, los escritos más trabajados y más estudiados que he hecho sobre la economía y la historia argentina" (p. 13). En particular,

... el análisis de los grandes consorcios financieros que hay en el país que hice en Frente Proletario (el consorcio Bemberg, el consorcio Tornquist). Hay un libro de siete capítulos que no se editó, sobre el conjunto de la estructura económica argentina. Posiblemente se hubiera llamado "La Argentina, su

7. "Charla entre N. Moreno y J. J. Sebreli a principios de 1976", p. 13. Lo conservado de este reportaje es su desgrabación mecanografiada, luego editada como boletín interno del PST con el título "Nuestra historia”. Evocaba Sebreli: “...conocí a uno de los creadores del trotskismo argentino, Nahuel Moreno, (...) nuestras conversaciones eran bastante francas, y además de las discusiones sobre lógica hegeliana, a las que era aficionado, me descubría con sentido del humor los aspectos más grotescos de la izquierda marginal" (Sebreli, 1987: 216). 
estructura económica y social", el que después tomé para los ensayos. (p. 13)

Y concluía: "Más o menos la mitad (...) de lo que escribe después Peña es trabajo de investigación mía (...) Peña colabora conmigo, es mi ayudante y es mi gran amigo también en esta época" (p. 14). ${ }^{8}$

¿Qué resultados concretos produjo esa elaboración? Se expresó en el carácter más sofisticado que adquirieron ciertos artículos del periódico partidario y en el lanzamiento a partir de mediados de 1949 de una revista teórica, Revolución Permanente. Pero, sobre todo, en la confección de una serie de documentos o precarios folletos durante 1948-1950, reeditados con el paso de los años en varias oportunidades. Entre ellos estaban "Tesis agraria", "El centrismo en cifras" y "Tesis industrial". ${ }^{9}$ También de esos años son "Cuatro tesis sobre la colonización española y portuguesa", "Tesis latinoamericana" y "La acumulación primitiva de capital en la Argentina". Si bien eran escritos de Moreno, fueron reivindicados por el conjunto del GOM-POR, en tanto operaron como materiales partidarios de estudio. Y el joven Peña cumplió un papel fundamental en la recolección de evidencia empírica. Esos textos, que en conjunto ocupaban algo más de un centenar de páginas, procuraban establecer una nueva perspectiva teórica a la organización. Se afirmó que, a diferencia de las otras corrientes de izquierda y del trotskismo, un "mérito del POR" habria sido, precisamente,

el intentar fundamentar su actividad en un análisis relativamente elaborado de la realidad argentina, de su formación histórica a través de las formas de producción de la vida social, del surgimiento, desarrollo y lucha de las clases sociales. Frente Proletario y Revolución Permanente dieron cuenta, en forma de artículos y tesis, de ese esfuerzo. (Coggiola, 2006: 171-172)

En el mismo sentido, se encontró en el GOM-POR "un persistente esfuerzo por explicar la coyuntura política a partir de un cuadro de la naturaleza de la formación social argentina y su peculiar estructura de clases. Moreno empuja a su grupo a leer y analizar los censos industriales, agrarios y de población, a rastrear afanosamente toda la literatura

8. Según Tarcus, esto "ponía de manifiesto" la "incomodidad de Moreno con la obra de Peña”, y se interroga: “¿Quién plagia a quién?” (1996: 306). La pregunta es irrelevante. El desafio es reconstruir el modo en que un conjunto de ideas fueron enhebrándose dentro de una corriente política y el papel cumplido por sus intelectuales.

9. Luego agrupados en N. Moreno, "La estructura económica argentina" (1959). En 1954 hubo una edición precaria de esta compilación, como separata de la revista Revolución Permanente. 
económica, sociológica e histórica que se publica por aquellos años" (Tarcus, 1996: 106).

Lo que resulta aún opaco y debe calibrarse mejor es el grado de influencia que estas elaboraciones tuvieron en el posterior desarrollo de la obra de Peña. ¿Se trataron sólo de "intuiciones" y "orientaciones" analíticas rudimentarias, que luego Peña no sólo "reelaboró y sustentó" en su adecuada medida, sino que incluso pueden desconectarse de su programa teórico? (Tarcus, 1996: 111). En este sentido, se hace necesario un examen riguroso de estos materiales de 1948-1950. Hasta el momento, más allá de alguna mención ocasional, se presenta como una tarea incompleta o superficialmente desplegada.

Comencemos con la "Tesis industrial". Aquí se ilustraba el crecimiento de la actividad manufacturera argentina, a partir de la evolución del número de establecimientos, personal ocupado y fuerza motriz entre 1895-1948. Lo hacía en base a un examen crítico de los censos y los recientes estudios de Adolfo Dorfman y otros investigadores. Se encontraba un esquema de "desarrollo combinado", que contraponía una producción concentrada y moderna en grandes empresas con una multitud de diminutos talleres de escasa complejidad. El eje del texto apuntaba a señalar el carácter dependiente y subsidiario de esta rama con respecto a los terratenientes y al capital extranjero, intentando demostrar que era falso el planteo de que la industrialización de un país atrasado implicaba su independencia económica con el imperialismo y el "fortalecimiento de una burguesía industrial antiimperialista". ${ }^{10}$ Cuestionaba el supuesto carácter "progresivo" de las políticas de "proteccionismo, intervencionismo estatal y nacionalizaciones", encontrando líneas de continuidad entre los gobiernos de Justo y Perón, y entre el "plan de reactivación económica" de Pinedo y el Plan Quinquenal del justicialismo. Se advertía sobre el dominio económico-político que ejercian los ingleses y el modo en que los grandes consorcios, como Tornquist, Bemberg y Roberts, controlaban la mayor parte de las industrias, bancos y empresas comerciales y de servicios del país. Ya estaba enunciado lo que luego sería el basamento del planteo de Peña acerca de la clase dominante y la ausencia de contradicciones entre un ala rural y un ala industrial:

La burguesía industrial argentina no es homogénea. Su sector más fuerte, más importante, está unido a las empresas imperialistas de dos formas, ya sea por sociedad directa o por acuerdos. Estos sectores no tienen ninguna oposición a los terratenientes ya que la mayoría de las veces éstos capitalizan

10. Varios artículos del periódico del GOM fueron en la misma dirección. Ver “¿Imperialismo argentino?", Frente Proletario, año II, n 16, 14 de mayo de 1948, p. 1. 
su ganancia en compra de tierras, o viceversa, los terratenientes capitalizan su renta en la industria. ${ }^{11}$

La "Tesis agraria" complementaba estos análisis. Señalaba la decisiva importancia del sector rural y el papel subordinado de la industria en la economía argentina. Apelando a la historia crítica de la plusvalía de Marx, afirmaba que las relaciones de producción en el campo no eran "esencialmente capitalistas, sino familiares". ${ }^{12}$ Intentaba demostrar el escaso rendimiento del trabajo agrícola, relacionándolo con el nivel de concentración de las explotaciones. Por otra parte, partiendo de considerar el grado de centralización de la propiedad y monopolio del suelo, identificaba cuatro actores. Uno eran los terratenientes, que "necesitan imperiosamente el trabajo agrícola, para valorizar su renta, y el mercado mundial con su exigencia de materias primas y de consumo". Un señalamiento clave: "Muchos terratenientes capitalizan su renta agraria en empresas industriales y viceversa. De ahí la prosapia estancieril de muchos grandes industriales y el ningún antagonismo entre los sectores más importantes de ambas clases". Respecto a los muy minoritarios "capitalistas agrarios", propietarios de los establecimientos modelos, cabañas y explotaciones mixtas, y "ejemplo de racionalización capitalista del trabajo", se afirmaba que "no tienen antagonismo con los terratenientes, ya que son una excrecencia de estos últimos". En cuanto a los "productores directos", la amplia mayoría de los agricultores, sus estratos más bajos quedaban homologados a la categoría de "campesinos pobres" de Lenin. Y a "los proletarios, permanentes y temporarios", se los determinaba por la relación de tipo familiar-paternal con el patrón, y el bajo grado de división del trabajo y mecanización del agro (excepto los obreros agrícolas de las estancias modelo). El Estado comercializaba las cosechas para salvar la valorización de la renta agraria e impedir que "el sobre-valor comercial vaya a manos del productor directo, del chacarero, y sí a las arcas de los más poderosos latifundistas y burgueses". Con ello se queria impugnar los planteos de grupos trotskistas como Octubre o GCI, que festejaban las características antioligárquicas y antiimperialistas del peronismo. En el mismo terreno polémico, se desmentía el carácter avanzado del capitalismo agrario local, aunque se negaba la existencia de reminiscencias feudales. ${ }^{13}$

11. "Tesis Industrial", 1948. La idea reaparece en "La Argentina actual económica y social", Frente Proletario, año II, N ${ }^{\circ}$ 20, 20 de agosto de 1948, p. 1.

12. "Tesis agraria", 1948. Todas las citas de este párrafo pertenecen al mismo texto.

13. Esto era motivo de frecuentes discusiones en el trotskismo. En " $\mathrm{El}$ centrismo en cifras" (febrero de 1950), Moreno reafirmaba la caracterización del país como "ca- 
Este programa de estudio aparecía sobredeterminado por una perspectiva histórica, buscando reconstruir los rasgos germinales del capitalismo vernáculo. A ello se refería "La acumulación primitiva de capital en la Argentina". Repasaba dicho proceso, a lo largo del siglo XIX y a partir de una contrastación bastante elemental con el esquema de Marx en El capital, introduciendo algunas variables básicas de análisis: la existencia de "una colonización típicamente capitalista con cerrado monopolio de la tierra", el peso de los terratenientes, la imposibilidad del chacarero para convertirse en propietario o arrendatario capitalista, la consecuente debilidad del mercado interno, las limitaciones de la industria y la supeditación al mercado mundial, entre otras (Moreno, 1960: 19).

Esta mirada hacia el pasado se extendía aún hacia más atrás. En "Cuatro tesis sobre la colonización española y portuguesa" (Moreno, 1957), se intentaba fundamentar el carácter esencialmente capitalista de esta última, empalmando con las posiciones que hacia esa época sostenia el historiador Sergio Bagú. Se afirmaba que las expediciones y la producción en el continente americano se habían organizado para obtener grandes ganancias colocando mercancías en el mercado mundial, sin inaugurar un sistema de producción capitalista, pues no había un ejército de trabajadores libres ni un mercado de fuerza de trabajo asalariada. Y era por ello que los colonizadores se habrian visto obligados a recurrir a otras relaciones de producción: esclavitud, encomienda, mita y yanaconazgo. Con ello se negaba el planteo más aceptado en la historiografia y en la propia izquierda (sobre todo, el comunismo, para justificar su estrategia de "revolución por etapas"), en el cual se destacaba el objetivo feudal de dicha empresa.

En otro extenso trabajo, "Tesis latinoamericana", se definía a los países del subcontinente bajo la categoría de "semicoloniales y atrasados", y de conjunto a toda la región como "apéndice de los EE. UU.". ${ }^{14}$ Examinaba las características del agro y la industria con el prisma del "desarrollo combinado", así como el rol desempeñado por el capital financiero. Escrutaba las clases sociales latinoamericanas (rasgos, función, dinámica), identificando a los terratenientes, la burguesía agente del imperialismo, la pequeña burguesía y el proletariado. Y buscaba interpretar la dinámica de la movilización obrera y de masas en la posguerra, así como al Estado y los principales movimientos políticos del área, sobre todo, aplicando la categoría de "bonapartista o semibonapartista" para varios de los gobiernos existentes (en especial, el peronismo).

pitalista atrasado", dado el "bajo nivel de desarrollo de las fuerzas productivas", no obstante ser una de las más "adelantadas" de las economías "semicoloniales".

14. “Tesis latinoamericana”, noviembre 1948. 
En la investigación que dio lugar a algunos de estos textos, Peña cumplió un papel, especialmente en lo que hace al relevamiento de fuentes y bibliografia. Pero el papel secundario del militante quinceañero en este proceso de elaboración se presenta como un dato fáctico: no hay evidencias de escritos propios, firmados por él. Su primera publicación registrada (bajo el seudónimo de $\mathrm{H}$. Radio) fue una nota aparecida en Frente Proletario en mayo de 1951, "La Argentina y el imperialismo", donde ratificaba la supeditación del país a la órbita inglesa y denunciaba "la demagogia peronista sobre el antiimperialismo y la industrialización". ${ }^{15}$ En los tres años siguientes no hemos encontrado otros artículos de Peña, y tampoco la redacción de folletos, que inició en 1956.

\section{La conflictiva relación entre el POR y Hermes Radio}

En el primer número de la revista Estrategia de la Emancipación $\mathrm{Na-}$ cional (en adelante, Estrategia), como complemento al ya referido texto sobre la colonización española y portuguesa de América, Peña reproducía una nota aclaratoria que Moreno le había enviado en agosto de 1957:

... he creído conveniente enviarte un viejo trabajo nuestro sobre la colonización española-portuguesa, a pesar de sus evidentes debilidades. Esto de "nuestro" es verdadero, vos lo sabés, en muchos sentidos. Es nuestro en tanto que trotskista, ya que es producto de años de fructíferas polémicas entre trotskistas. Es también nuestro, en el sentido que vos colaboraste como nadie en el estudio e investigación que culminó en la apresurada tesis. ${ }^{16}$

Peña contestaba:

Efectivamente, desde 1943 el camarada Moreno ha realizado diversos trabajos de investigación e interpretación sobre problemas fundamentales para el marxismo latinoamericano. A partir de 1948 colaboré con él en varios de esos trabajos, de modo que mi juicio sobre ellos no puede estimarse imparcial, pero creo que hay razones objetivas para considerarlos como los aportes más valiosos hechos hasta hoy para la elaboración de un auténtico pensamiento marxista latinoamericano, y

15. H. Radio, "La Argentina y el imperialismo", Frente Proletario, año V, No 48, 1 de mayo de 1951, pp. 9-12.

16. Nota de N. Moreno a M. Peña, en Moreno, 1957: 83-84. 
esto sin cerrar los ojos a las obvias deficiencias formales y de contenido. ${ }^{17}$

Pero si este "amable" intercambio público sirve para ilustrar el juicio que Peña hacía de la elaboración teórica del GOM-POR y el modo como habían influido en sus propias concepciones, las cuales para esa época ya comenzaban a mostrar una extraordinaria creatividad y madurez, todo ello no puede ocultar un dato incontrastable: la áspera y fallida relación que la dirección del grupo tuvo con Radio como militante e intelectual revolucionario, y el modo tortuoso como éste debió procesar esta doble condición. La paradoja que se nos presenta es notable: la organización contaba con un joven estudioso e investigador autodidacta de ya probada capacidad de trabajo e inteligencia, formado en los planteos politicos y programáticos del marxismo, pero no encontró la forma de canalizar esta potencialidad de manera productiva, haciendo naufragar la posibilidad de convertirlo en un gran intelectual "orgánico" de la corriente.

El tipo de exigencias de la actividad partidaria acabaron abrumando al joven militante. Nada de esto fue asumido de manera pública, pero ciertos materiales internos, permiten reconstruir este proceso. En un borrador del PST sobre la historia partidaria, se ubicaba a Peña como una de las "figuras" entre los años 1947-1952, pero se apelaba a una suerte de contraposición entre su actividad intelectual y su disposición militante: "Milcíades Peña, que nunca fue un gran militante, era sobre todo un gran teórico, gran propagandista de nuestras posiciones". ${ }^{18}$ En un escrito de circulación aún más restringida, el propio líder de la corriente reconoce que el distanciamiento o la "falta de compromiso" de Peña comenzó rápido, "cuando le exigimos ir a Avellaneda y militar en el movimiento obrero en el 49". ${ }^{19}$ Según informes del CC del POR de marzo de 1950, Radio todavía asistía, con voto, a sus reuniones ampliadas con la presencia de cuadros destacados. Ya no figuraba como miembro del $\mathrm{CC}$, sino como militante de la Regional La Plata. ${ }^{20}$ Aún se desempeñaba como secretario de redacción del periódico. Su inestabilidad dentro del POR persistió. El 18 de septiembre de 1952, Radio escribió desde La Plata: "Por la presente solicito se me otorgue licencia hasta fin de año, eximiéndome de las tareas de militancia. Las razones de mi pedido son puramente personales (cansancio, disminución de mi capacidad de

17. Nota de M. Peña, en Moreno, 1957: 84.

18. "Historia del Partido", documento interno del PRT-La Verdad, 1970, pp. 6-7.

19. "Transcripción de un curso sobre la historia del partido dictado por Moreno, 1968-1969", p. 12.

20. Documentación interna del POR del 18 de marzo de 1950, informando de una reunión de $\mathrm{CC}$ ampliado de 23 asistentes, entre los que figuraba Peña. 
trabajo y realización de un trabajo lucrativo que me demanda muchas horas por día)". ${ }^{21}$ Ya sin responsabilidades de dirección, Peña continuó en los equipos partidarios por un tiempo más. Durante 1953-1954, su alejamiento de la militancia se hizo más claro y sus relaciones con el partido fueron muy agrias, quedando en categoría de "simpatizante" del mismo, tal como puede advertirse en el intercambio de cartas que desplegó con la dirección.

Desde comienzos de 1953 se discutía en el POR la necesidad de volver a editar una revista teórica, tras haber concluido la experiencia de Revolución Permanente. Peña aparecía como una pieza clave para una empresa de este tipo. El Buró Político no sólo evaluaba las dificultades financieras del proyecto: "El aspecto Redacción es sumamente débil: Moreno se compromete a hacerlo marchar en base a su trabajo fundamentalmente, con la ayuda de Radio y el hermano de B (...), con los cuales se encararia la organización de archivo, ficheros de redacción, etc.". ${ }^{22}$ Pero el objetivo de la revista no pudo concretarse en ese período. Mientras tanto, el vínculo entre Radio y el POR afrontaba constantes turbulencias. Sabemos que en agosto de 1953 solicitó el reingreso a la organización, pero el Buró Político lo rechazó, hasta tanto él no aclarara ciertas acusaciones de deslealtad que amenazaban con ubicarlo como "enemigo del partido", concluyendo: "al margen de sus innegables dotes intelectuales, lo considera un elemento de cuidado y sumamente inseguro". ${ }^{23}$ Peña contestó duramente a ello en otra carta donde manifestaba las fuertes deficiencias estructurales en el funcionamiento del grupo, el carácter "practicista" de su dirección y la excesiva centralización en la figura del líder, pero al mismo tiempo destacaba que "el POR es, por su programa y composición social, una organización proletaria, marxista revolucionaria (...) es lo mejor que ha dado la clase obrera del país en su 'década infame' 1943-53. Y el programa del POR es en lo esencial, pese a su estado incipiente (...) el punto más alto alcanzado por el marxismo latinoamericano". ${ }^{24}$

En ese entonces, el POR estaba en mutación. Venía de más de un lustro de denuncia del régimen peronista, por la inconsecuencia con la que aplicaba sus supuestas medidas antiimperialistas y antioligárquicas, por sus politicas de control totalitario sobre el movimiento obrero y por el modo en que había contribuido a montar una poderosa burocracia sindical. Contra esta última el partido habia luchado desde las bases, participando en comisiones internas de delegados y listas de oposición.

21. Carta de H. Radio al Buró Político del POR, 18 de septiembre de 1952.

22. Orden del día de la reunión del Buró Político del POR, 20 de abril de 1953.

23. Carta del Buró Político del POR al camarada Radio, 17 de agosto de 1953.

24. Carta de Radio al Buró Político del POR, 22 de agosto de 1953. 
Pero hacia 1953 comenzó una autocrítica, que condujo a un progresivo viraje en la línea de la organización, lo cual se hizo explícito en octubre durante su IV Congreso. Ahora se denunciaba el "propagandismo" y el carácter "abstracto" y "esquemático" de muchas de los planteamientos del partido, que lo habrian acercado al "contrerismo" antiperonista, sosteniendo la necesidad de nuevas tácticas y métodos de trabajo que lo ayudaran a un vínculo aún más efectivo con la clase obrera. El POR también comenzó a explorar la posibilidad de una actuación legal. La vía elegida fue intervenir en la crisis que sacudia al PS, donde un sector de la dirección y de los cuadros medios, conducido por los Dickmann, impulsó el PS de la Revolución Nacional (PSRN), para participar con fórmulas propias en la elección de 1954. Varios grupos trotskistas se sumaron a una organización que presentaba una notable heterogeneidad. El POR se dispuso a hacer "entrismo" en el PSRN, pretendiendo controlar su federación bonaerense. El viejo nombre del periódico, Frente Proletario, fue reemplazado a partir de julio por el de La Verdad.

Todo esto significaba un importante reajuste en las caracterizaciones y en la línea del POR, que fueron sintetizadas por Moreno en un folleto, editado en ese momento: 1954, año clave del peronismo. Ahora se advertía que la clave estaba en enfrentar la fuerte ofensiva de "colonización yanqui" que operaba sobre el país y toda Latinoamérica desde fines de los años 30, con la colaboración creciente de la Iglesia y de la burguesía industrial y agraria, a la cual el peronismo no ofrecía más que una tibia e inútil resistencia, más bien una adaptación acorde a su carácter "bonapartista", lo cual dejaba a las masas obreras desguarnecidas frente a los planes de superexplotación y a la propia amenaza de los golpes militares reaccionarios. Bajo el abrigo de estas nuevas definiciones y sus muy modestas fuerzas, la "Federación Bonaerense del PSRN" intervino en los sitios de trabajo, en los sindicatos y en las calles, contra el levantamiento militar de junio de 1955 y el cívico-militar de septiembre, que finalmente condujo a la caída del peronismo.

Peña se alineó con estas readecuaciones políticas y organizativas del POR. Lo hizo desde una posición especial, pues hacia 1954 seguía sin ser miembro "orgánico" de la agrupación, sino "simpatizante". De hecho, sabemos que ésta discutía qué organismo debía establecer vínculos con él: "Radio será atendido por la zona Este". ${ }^{25} \mathrm{~A}$ partir del siguiente año, sus vínculos con el partido, aún con mucha dificultad, volvieron a restablecerse más fluidamente, a partir de un nuevo pedido de reingreso a sus filas.

25. Resoluciones del Buró Político del POR, 21 de julio de 1954. 


\section{Silvio Frondizi}

Esta ubicación quedó demostrada y debió pasar una prueba: lo que podriamos llamar el "caso Silvio Frondizi". Este destacado intelectual, que fue asumiendo una identidad socialista, ya poseía una larga trayectoria universitaria. Además, agregaba el hecho de ser parte de una familia de importantes figuras politicas y académicas. En 1955-1956 había publicado los dos tomos de su mayor y más ambiciosa obra, La realidad argentina. Ensayo de interpretación sociológica. En el primero abarcaba las características del sistema capitalista, tanto a nivel mundial como en la Argentina, procurando mostrar los rasgos de las distintas clases sociales y fuerzas politicas que configuraban la escena local, para arribar a una conclusión: el fracaso histórico de la burguesía nacional como alternativa progresiva. En el segundo, exploraba la teoría de la revolución socialista y el modo como se articulaba en sus tareas, sus programas y sus fases dentro del área continental y nacional, ejerciendo una crítica de todas las corrientes político-ideológicas, incluso del trotskismo, al cual le negaba el carácter de sintesis superadora del estalinismo contrarrevolucionario. Frondizi le dedicó seis páginas al POR, ponderando algunos de sus análisis sobre el imperialismo (a los cuales emparentaba con su propia "teoría de la integración mundial") y la clase dominante, pero impugnando los planteos esenciales que ese grupo había hecho en sus primeros años sobre el justicialismo: “...Moreno (...) al negarle a la burguesía nacional un carácter dinámico propio, fue incapaz de comprender el papel del peronismo en la vida política argentina..." (Frondizi, 1956: 99). Desde principios de los años 50, Frondizi fue constituyendo un núcleo teórico-cultural, que luego convirtió en organización política, el Movimiento de Izquierda Revolucionaria-Praxis. A sus primeros impulsores, Marcos Kaplan, Eugenio Werden y el peruano Ricardo Napurí, luego se sumó una numerosa camada de intelectuales, estudiantes y activistas populares, aunque sin mayor capacidad de incidir ni en el movimiento social ni en la lucha política. Hacia mediados de los 60, acabó disolviéndose. Hacia 1954 Peña había tenido vínculos intelectuales y laborales con Frondizi y su grupo. En aquel año, incluso, Peña había sido uno de los tantos que había colaborado con la redacción de un subcapítulo del tomo II de $L a$ realidad argentina, dedicado al problema de la "expansión industrial, imperialismo y burguesía nacional", tal como su autor lo agradecía en una nota que quizás sea una de las primeras menciones públicas de Peña bajo su nombre (Frondizi, 1956: 139).

A comienzos de 1955, la dirección del POR le cuestionó a Peña, en proceso de reinserción orgánica en el partido, sus vínculos con Frondizi y su grupo. Hubo un cruce de cartas entre Radio y el Buró Político con 
eje en esta cuestión. El 11 de abril, Peña justificaba esas relaciones: "Mi colaboración con el grupo Praxis es de tipo intelectual y técnico. Intercambio con ellos libros y otros materiales, publico trabajos teóricos en CESA [un periódico impulsado por ese grupo], etc. Además, colaboro en la Editorial Praxis (diagramado de carátulas, publicidad, etc.)..."; pero al mismo tiempo aclarando que "considero que el grupo Praxis es una organización centrista de izquierda (...) es enemigo político nuestro, en el sentido de que combate sistemáticamente al trotskismo". A pesar de cuestionar a Moreno por sus métodos de "terrorismo ideológico", concluía: "Mi actitud ante las posiciones políticas del grupo Praxis queda indicada por el hecho de que soy simpatizante del POR y no de aquel grupo", pues el POR es "la única organización proletaria revolucionaria que merezca llamarse tal en la Argentina de 1955". ${ }^{26}$ Una semana después, desde el POR se respondía con una extensa carta donde recusaba los planteos de Radio, alertando que Praxis (a través de Kaplan y Napurí) había lanzado una campaña de calumnias contra el partido, a las cuales aquél habría cedido. Para que el POR lo considerara un "simpatizante honesto", se lo intimaba a repudiar esos planteos y a reconocer que Praxis no era más que "una típica secta pequeño-burguesa, centrista de izquierda, que está contra el programa y la forma de organización bolchevique" ${ }^{27}$ Las exigencias fueron rechazadas por Peña, casi dos meses después, aunque volvía a señalar:

Sigo compartiendo íntegramente todas las posiciones programáticas del Partido, continúo aceptando la línea que da quincenalmente La Verdad, en fin, creo siempre que el POR es teórica y prácticamente el punto más alto alcanzado por el marxismo en América Latina y pienso que hay que militar en él y que pronto pediré mi reintegro como militante. ${ }^{28}$

Este intercambio epistolar retrataba un círculo vicioso, una suerte de juego de suma cero entre Peña y el POR. Seis meses después, ello se zanjó, precariamente, con el reingreso formal de Radio a las filas de la organización, para lo cual éste aceptó enviar la carta de "ruptura" y repudio público a Praxis y a sus planteos, que el POR le exigía. Como Peña informaba al Buro Político el 14 de diciembre, ese mismo día le entregó la exigida carta a Praxis, con otra personal a Frondizi, donde en cierto modo se justificaba de dar dicho paso: "habiendo yo solicitado

26. Carta de H. Radio al Buró Político del POR, La Plata, 11 de abril de 1955.

27. Carta de Moreno (en nombre del Buró Político del POR) al camarada Radio, Buenos Aires, 18 de abril de 1955.

28. Carta de H. Radio al Buró Político del POR, La Plata, 7 de junio de 1955. 
el reingreso al mismo [se refiere al POR] como militante me exige llenar una serie de recaudos, y ante todo demostrar que acato la disciplina política de la organización". ${ }^{29}$

El carácter profundo con el que Peña encaró lo que podría llamarse esta "segunda fase de militancia orgánica en el POR" está dado por la propia deriva que tuvo la ruptura de éste con Frondizi. No se conoce qué respuesta tuvo la carta antes mencionada. En todo caso, transcurrido unos meses, Radio redobló el ataque contra Frondizi/Praxis. Lo hizo en lo que constituyó el primer folleto importante publicado por Peña, a través de los canales de la organización. Su título: Profesores y Revolucionarios. Un trotskista ortodoxo responde al profesor Silvio Frondizi. En ese extenso texto, Radio confrontaba con el fundador de Praxis (al cual, todo el tiempo lo identificaba por sus siglas S.F.), desde una delimitación de identidades muy estricta: "Nuestra primera divergencia con el profesor S.F. -que es también el primer plano de toda nuestra polémica con él, que no comienza hoy- está dada por las distintas actividades a que nos dedicamos". Y a partir de alli ubicaba lo que podría definirse como un claro campo de diferenciación Peña-Frondizi:

Los trotskistas ortodoxos somos y queremos ser, ante todo, militantes de la clase obrera, actores lo más activos posible de la lucha de clases. El profesor S.F., en cambio, se reserva principalmente un papel de "instructor" o "entrenador" revolucionario $[. .$.$] que prepara dirigentes de la revolución sin participar$ empero en la lucha de clases... (Peña/Radio, 1956: 1)

Más aún:

Por lo general, los intelectuales que se acercan al movimiento revolucionario no hacen un serio esfuerzo teórico, y sobre todo práctico para integrarse en los batallones de vanguardia del proletariado revolucionario [...] Y firmes en ese convencimiento tienden a encerrarse con su círculo de adeptos, para insistir en que el movimiento revolucionario vaya hacia ellos [...], y no a la inversa. Que es sin embargo el único camino viable si es que efectivamente se trata de construir un instrumento capaz para combatir y abatir el Poder de la burguesía, y no una "escuela" más de filosofia, todo lo marxista y revolucionaria que se quiera en la instrucción que imparta, pero totalmente inoperante para dirigir a la clase obrera. (ídem, p. 1)

29. Carta de H. Radio al Buró Político del POR (conteniendo copia de carta a S. Frondizi), La Plata, 14 de diciembre de 1955. 
A continuación de este encuadre, lo que hacía Peña era una reivindicación cerrada del trotskismo:

El profesor S.F. es a la vez antiestalinista y antitrotskista [...] Pero, cuáles son los fundamentos del antitrotskismo frondizista? Ni hechos ni razones. Apenas especulaciones subjetivas sobre el "sectarismo" trotskista y alguna que otra baratija chismográfica en torno a la "personalidad de Trotsky". Lo cierto es que fuera del trotskismo ortodoxo no existe en el mundo otra corriente proletaria con un programa, una organización y una experiencia revolucionaria. (idem, p. 3)

En la óptica de Radio las posiciones de Frondizi eran "boberías inconscientes" o, en el mejor de los casos, "racionalizaciones, justificaciones a posteriori" para negarse a acatar "la disciplina y el programa" revolucionario (p. 4). Radio intentó demoler cada una de las impugnaciones que Frondizi dedicó contra el trotskismo y repasó la trayectoria y las posiciones del GOM-POR-Federación Bonaerense del PSRN, que él asumía como propias. En particular, lo hizo discutiendo el problema del peronismo y las dificultades para adoptar una caracterización y política correctas por parte de su partido, sin conceder ningún margen de crítica sobre el evidente vaivén que su corriente había exhibido.

\section{La producción de un intelectual trotskista}

A partir de 1955 y durante cerca de un lustro, Peña volvió a quedar vinculado orgánicamente con la corriente trotskista. Durante los dos primeros años de ese período fue cuando redactó el texto original de Historia del pueblo argentino, una tarea condicionada por su encuadre militante, pero que desplegó de manera autónoma, por su propia iniciativa y en la que el autor pudo alcanzar sus mayores niveles de creatividad, inteligencia y peculiar estilo narrativo. Auxiliado con la teoría de la revolución permanente, la ley del desarrollo desigual y combinado y otros aportes de la teoría marxista, y con el propósito de destruir las mistificaciones historiográficas erigidas por el liberalismo y el revisionismo histórico, Peña ofreció en su texto todo un modelo de análisis sobre la evolución económica, social y política del país a lo largo de un siglo y medio. Paradójicamente, fueron las clases dominantes, sobre todo, en sus limitaciones objetivas y subjetivas para comportarse como un factor avanzado de la historia, las que aparecieron más atendidas (y enjuiciadas) en su examen, antes que el pueblo argentino invocado en el título, sobre cuya comprensión apenas adelantó algunos elementos.

Pero otra de las labores de Peña en esa etapa fue la de convertirse en 
una suerte de publicista y argumentador de las posiciones de su tendencia politica. Todo ocurrió en un tiempo convulsivo. Una vez derrocado el peronismo, el PSRN fue ilegalizado y disuelto. Como hemos visto, el POR se expresaba a través de la Federación Bonaerense de ese partido. Ya sin esa denominación, durante 1956-1957 la agrupación impulsó un nuevo órgano de prensa, Unidad Obrera. Radio reivindicó el accionar del grupo durante el ciclo que condujo al golpe cívico-militar de 1955. Lo hizo en un largo trabajo, aparecido por vez primera en septiembre de 1957, como artículo de Estrategia, bajo el título “¿Quiénes supieron luchar contra la 'revolución libertadora' antes del 16 de septiembre de 1955?", que inmediatamente adoptó también la forma de un folleto (reeditado en varias oportunidades). Alli reproducía y analizaba una serie de volantes y notas de La Verdad (en algunas de las cuales el propio Peña había colaborado), concluyendo que el grupo había sido el único que aún luchando "contra la marea montante del golpe clericalpatronal-imperialista, supo conservar su independencia frente al gobierno peronista y denunciar ante la clase obrera el tremendo desastre a que conducía la desastrosa política de la dirección peronista" (Peña/ Radio, 1957a: 137).

En realidad, la plena soberanía del grupo con respecto al peronismo no estaba asegurada. La corriente se insertó en el proceso de lucha de la clase trabajadora comúnmente llamada "resistencia peronista": participó en la dirección de luchas obreras, comités de huelga y comisiones internas de delegados en fábricas metalúrgicas, textiles y de la carne; logró montar agrupaciones gremiales combativas; y fue parte del proceso de reorganización sindical antipatronal y antiburocrática expresada en la Comisión Intersindical y las 62 Organizaciones. Desde 1957 constituyó el llamado Movimiento de Agrupaciones Obreras, que fue más conocido por el periódico que comenzó a editar en julio, Palabra Obrera. Pero, como derivado de su estrategia, el grupo asumió la política del denominado "entrismo en el peronismo". En los dos años siguientes, la pequeña organización expandió algo sus filas, sin superar los 250/300 militantes, la mayoría implantados en el movimiento obrero, aunque sin lograr traducir su penetración sindical en influencia política. Ello ocurrió, en buena medida, por la propia estrategia de camuflaje en el peronismo realizada por Palabra Obrera, que constituyó una adaptación a la conciencia e identidad política burguesa y de conciliación de clases de los trabajadores. Peña no sólo no desplegó reparos a dicha orientación, sino que se encargó de hacer uno de los intentos más profundos de fundamentarla teóricamente. Se trató de otro muy extenso artículo, "Peronismo y revolución permanente: política obrera y política burguesa para los obreros", publicado en junio de 1958 también en la revista Estrategia. Apelando a un rastreo por los referentes "clásicos" 
del socialismo, explicaba cómo podía conciliarse el planteo de la lucha por la "legalidad para Perón y el peronismo" con el hecho de que "nuestro programa es el del trotskismo ortodoxo y que tenemos una actitud muy crítica ante la vieja dirección peronista" (Peña/Radio, 1958: 54). El entrismo, decía, buscaba "ayudar a la organización autónoma de la clase obrera y a su hegemonía en el frente nacional" (p. 69).

En ese período, las tareas en torno a la revista teórico-política Estrategia, que alcanzó a publicar tres números entre 1957-1958, fue lo que concentró la mayor dedicación de Peña. Si bien en Palabra Obrera recayó parte del compromiso por impulsarla, fue él quien se constituyó en el eje de esta experiencia, ejerciendo las funciones de editor responsable. El objetivo fue el de una revista de izquierda amplia, entendida como "tribuna del pensamiento revolucionario argentino", en donde las posiciones de la corriente trotskista pudieran trabarse en polémica con representantes de otras tendencias o individuos del campo marxista (incluso poco emparentadas con las posiciones de aquella). Por eso, además de los textos de Peña y Moreno, alli aparecieron los de Puiggrós, de Frondizi y Werden (de Praxis), del filósofo Carlos Astrada, del poeta e historiador Luis Franco (amigo de Peña y de la corriente) o de los artistas concretos Alfredo Hlito y Tomás Maldonado, entre otros.

Fue en Estrategia donde Peña publicó, ya sin seudónimo, acaso dos de sus trabajos más extensos, importantes y documentados. Estaban consagrados al tema que venía ocupando su interés desde hacía varios años: las características de la clase dominante argentina, en especial de la burguesía industrial, y de la propia industrialización y sus vínculos con el imperialismo. En buena medida, todo lo que luego este autor produjo sobre el tema fue una derivación o complementación de estos trabajos. Nos referimos a los textos que publicará en Fichas de investigación económica y social (1964-1965), en especial su célebre debate con J.A. Ramos, que luego de su muerte se editó como libro independiente bajo el título de Industria, burguesía industrial y liberación nacional (1974).

El primer artículo de Estrategia a destacar es "Rasgos biográficos de la famosa burguesía industrial argentina", donde examinaba esta clase, buscando desmitificar "las pasiones nacional-revolucionarias que le atribuyen sus exaltados festejantes", en los que incluía a Puiggrós, Ramos, Eduardo Astesano y otros (Peña, 1957b: 45). En función de estos presupuestos realizaba una notable disección de este sector social, a partir de un relevamiento bibliográfico y, sobre todo, empírico, de carácter exhaustivo, que lo conducía a un examen de los grupos económicos y su composición de capital y propiedades, detectando orígenes, funciones y entrelazamientos. Una hipótesis fuerte del texto golpeaba en el plexo de toda la argumentación clásica sobre la clase dominante, 
recuperando casi milimétricamente la argumentación esbozada en la "Tesis industrial" y las otras elaboraciones del GOM-POR de 1947-1949, pero enriqueciéndola. Afirmaba la hipoteca que la industria argentina tenía respecto al capital extranjero monopólico y señalaba:

La burguesía industrial argentina ha nacido estrechamente ligada a los terratenientes, como diferenciación en su seno. Ambos sectores, industrial y terrateniente, se entrelazan continuamente, borrando los imprecisos limites que los separan, mediante la capitalización de la renta agraria y la territorialización de la ganancia industrial, que convierte a los terratenientes en industriales y a los industriales en terratenientes. (p. 47)

Este planteamiento tuvo en las décadas siguientes un gran desarrollo en las ciencias sociales, siendo recuperadas, total o parcialmente, desde diversas perspectivas teórico-ideológicas. En todo caso, el objetivo del escrito giraba alrededor del planteo de que "la burguesía industrial argentina, por razones sociales y económicas, tiene un interés no menor que el capital imperialista y los terratenientes en la perpetuación del atraso del país y de la explotación imperialista" (p. 46). En ese sentido, se trataba de una "clase contrarrevolucionaria y antinacional"; en definitiva, "sólo la clase obrera respaldada en las masas trabajadoras del campo y la ciudad tiene interés y capacidad para liquidar a los terratenientes y al capital imperialista" (p. 79). Y dado que esos objetivos "democráticos y nacionales" sólo podían ser realizados bajo dirección proletaria, la revolución argentina sería "obrera y socialista por sus métodos y por la clase que la realiza” (p. 80). La argumentación se hallaba informada por un intento de aplicación de la teoría de la revolución permanente de Trotsky.

En el otro artículo aludido de la revista, "El imperialismo y la industrialización argentina", Peña ofrecía otro estudio pormenorizado y sólidamente argumentado acerca de la burguesía industrial y de sus inconfundibles vínculos con el capital extranjero. Analizaba la política del capital financiero, el mecanismo de exportación de capitales y la naturaleza de la industrialización en términos teóricos internacionales, para luego abocarse a un retrato de lo que denominaba "pseudoindustrialización argentina", presentada como "parodia de o caricatura de industrialización", pues "no subvierte la vieja estructura, sino que se inserta en ella" (Peña, 1957c: 51). Enunciaba las deficiencias estructurales de esta rama, calculando la composición técnica del capital y los indices de descapitalización que la signaban, y el papel que en la perpetuación del atraso y del subdesarrollo cumplieron los imperialismos inglés y norteamericano. Las conclusiones se acoplaban a las posturas 
que la corriente venía sosteniendo: "La Argentina es un país atrasado y semicolonial y su industria participa de ambas características", por lo cual, para enfrentar estos límites sólo podía confiarse en la revolución y la consiguiente planificación estatal; de otro modo, "la industrialización del país será socialista, impulsada por los obreros, peones y chacareros adueñados del poder, o no será" (pp. 89-90). Pocas veces desde el trotskismo se había llegado a niveles tan sofisticados de indagación socioeconómica del capitalismo local.

\section{$* * *$}

El tercero y último número de la revista Estrategia fue editado en junio de 1958. Durante el resto de ese año y el que continuó, el proyecto perduró sólo con la publicación de una serie de folletos, bajo el título de Cuadernos de Estrategia. Entre ellos estaban algunos de los trabajos antes mencionados, como "La estructura económica argentina", de Moreno, y los de Peña/Radio en polémica con Frondizi y acerca de las posiciones del trotskismo durante la caída del peronismo. A estos se agregaban las transcripciones de dos cursos de iniciación política marxista, uno dictado por Peña y el otro por Moreno, organizados por agrupaciones estudiantiles de la Facultad de Ingenieria de la UBA en 1958-1959. Las del primero fueron recientemente reeditadas (Peña, 2000). Durante el transcurso de 1959, Peña produjo su distanciamiento orgánico definitivo con Palabra Obrera. Y en los seis años siguientes, se orientó en una perspectiva independiente, cuyo resultado intelectual más destacado fue la edición de la revista Fichas, en donde volcó su elaboración, sobre todo de los años precedentes, aunque también incorporó algunas nuevas producciones (ver Camarero, 1998).

Enunciemos algunas pocas conclusiones que surgen de toda la exposición precedente. Los años formativos y de la primera militancia en las filas del trotskismo por parte de Peña, los que van de 1947 a 1950, fueron los que cimentaron algunas de las concepciones básicas de su proyecto intelectual, en especial, las que refieren al estudio de la clase dominante, del carácter atrasado y semicolonial del capitalismo argentino, de la pseudoindustrialización y del fenómeno peronista. Es obvio que no todo lo que él luego elaboró se debe o se puede explicar sólo a partir de estas experiencias políticas, planteamientos teóricos e hipótesis embrionarias provenientes de aquellos años, pero la ignorancia o subestimación de estos elementos abona a una interpretación equívoca acerca de los caminos de construcción del pensamiento y la obra de Peña. Entre 1955 y 1959 Peña desplegó el grueso de sus investigaciones sociológicas e historiográficas, aunque una buena parte de los textos que las canalizaron fueron publicados con posterioridad. El 
dato a no desestimar es que fue durante esos cuatro años cuando, al mismo tiempo, él retomó sus vínculos orgánicos con el trotskismo. Es decir, se trató de una elaboración teórico-política mediada por una inserción militante, aunque, como hemos visto, reiniciada de manera muy convulsiva, dada su tensa relación con la dirección partidaria. Si bien todo esto no parece acreditar una mirada que tienda a concebir ambas dimensiones, la de la adscripción politico-partidaria y la de la actividad teórica, como deseable e ineluctablemente escindidas e incompatibles, sí exige reconocer que, en el caso aquí considerado, dicha articulación fue procesada con un nivel muy alto de conflictividad.

Nos queda identificada una experiencia histórica, la de un grupo revolucionario al que no le faltaron despliegue teórico o intelectuales, pero el lugar de estos últimos estuvo acotada a las necesidades coyunturales o instrumentales de la organización. Ello implicó una amenaza o incapacitación a la propia función del intelectual y un desperdicio de su potencialidad creativa. Del caso analizado también se desprende un cuestionamiento a la competencia explicativa de los planteos teóricohistoriográficos que sólo pueden concebir a los intelectuales críticos sin partido y extraños a cualquier movimiento social, como aventuras individuales de destino trágico, sin siquiera plantear como un problema a resolver la conexión con los sujetos sociales y politicos de la lucha emancipatoria. No es posible establecer ninguna regla general ni generalizaciones indebidas. En cualquier caso, la historia de Peña brinda algunos insumos para reflexionar sobre los vínculos históricamente ocurridos y potencialmente deseables entre intelectual revolucionario y partido, entre teoría y praxis.

\section{Bibliografia}

- Acha, Omar (2009), Historia critica de la historiografia argentina: las izquierdas en el siglo XX, Buenos Aires: Prometeo Libros.

- Alexander, Robert (1973), Trotskyism in Latin America, California: Hoover Institution Press, Stanford University.

- Camarero, Hernán (1998), “¿Un testamento político? Reflexiones sobre la clase obrera en torno a un artículo de Milcíades Peña", Dialéktica, revista de filosofía y teoría social, año VII, $\mathrm{N}^{\circ}$ 10, julio, Buenos Aires, pp. 67-80.

- Coggiola, Osvaldo (2006), Historia del trotskismo en Argentina y América Latina, Buenos Aires: Ediciones ryr (1 ${ }^{\mathrm{a}}$ ed., 1985-1986).

- Frondizi, Silvio (1956), La realidad argentina. Ensayo de interpretación sociológica, tomo II: La revolución socialista, Buenos Aires: Praxis.

- Galasso, Norberto (2007), Aportes criticos a la historia de la izquierda argentina. Socialismo, peronismo e izquierda nacional, Buenos Aires: Nuevos Tiempos. 
- González, Ernesto (coord..) (1995), El trotskismo obrero e internacionalista en la Argentina, tomo I: Del GOM a la Federación Bonaerense del PSRN (1943-1955), Buenos Aires: Antídoto.

- Moreno, Nahuel (1957), "Cuatro tesis sobre la colonización española y portuguesa", Estrategia de la Emancipación Nacional, año I, $\mathrm{N}^{\circ}$ 1, septiembre, pp. 81-91 ( $1^{\text {a }}$ ed., 1948).

- (1959), "La estructura económica argentina", Cuadernos de Estrategia, Buenos Aires: Estrategia.

- (s/f), "Tesis latinoamericana", Buenos Aires: Ediciones Sociales $\left(1^{a}\right.$ ed., 1948).

- (1960), "La acumulación primitiva de capital en la Argentina", La Plata: Edición del Movimiento Estudiantil "Liberación" (1 $1^{a}$ ed., 1949).

- Peña, Milciades (1956), Profesores y Revolucionarios. Un trotskista ortodoxo responde al profesor Silvio Frondizi, Buenos Aires: s/d (bajo seudónimo de Hermes Radio).

- (1957a), “¿Quiénes supieron luchar contra la 'revolución libertadora' antes del 16 de septiembre de 1955?”, Estrategia de la Emancipación Nacional, año I, $N^{\circ} 1$, septiembre, pp. 93-137 (bajo seudónimo de H. Radio).

- (1957b), "Rasgos biográficos de la famosa burguesía industrial argentina", Estrategia de la Emancipación Nacional, año I, $\mathrm{N}^{\circ}$ 1, septiembre, pp. 43-80.

- (1957c), "El imperialismo y la industrialización argentina", Estrategia de la Emancipación Nacional, año I, $\mathrm{N}^{\circ}$ 2, diciembre, pp. 43-93.

- (1958), "Peronismo y revolución permanente: política obrera y política burguesa para los obreros", Estrategia de la Emancipación Nacional, año II, $\mathrm{N}^{\circ}$ 3, junio, pp. 54-101 (bajo seudónimo de H. Radio).

- (1974), Industria, burguesía industrial y liberación nacional, Buenos Aires: Fichas.

- (2000), Introducción al pensamiento de Marx (Notas inéditas de un curso de 1958), Buenos Aires: El Cielo por Asalto.

- (2012), Historia del pueblo argentino, Buenos Aires: Emecé.

- Rojo, Alicia (2012), "Los orígenes del trotskismo argentino: de los años 30 al surgimiento del peronismo. Elaboraciones teórico-políticas y vínculos con la clase obrera", Archivos de historia del movimiento obrero y la izquierda, año I, $\mathrm{N}^{\circ} 1$, septiembre, pp. 103-125.

- Sebreli, Juan José (1987), Las señales de la memoria, Buenos Aires: Sudamericana.

- Tarcus, Horacio (1996), El marxismo olvidado en la Argentina: Silvio Frondizi y Milciades Peña, Buenos Aires: El Cielo por Asalto.

- Veiga, Raúl (2006), El Tigre de Pobladora. Diálogos inéditos con Nahuel Moreno, Buenos Aires: El Socialista. 
Resumen: Milcíades Peña fue uno de los más importantes intelectuales de la izquierda argentina durante el siglo XX. Propuso una visión marxista original y crítica sobre el pasado nacional, la estructura socioeconómica del país, la clase dominante y el peronismo. En este artículo, a partir del análisis de fuentes primarias, se examinan asuntos poco explorados: el modo en que Peña se insertó en una de las tendencias del trotskismo argentino; las características teóricas, politicas, programáticas y organizativas de dicha corriente; y la incidencia que esta experiencia militante tuvo en la formación intelectual de Peña. La hipótesis propuesta es que, si bien la producción teórica de Peña luego fue cobrando una extraordinaria lucidez y autonomía creativa, apenas puede comprenderse sin sus contextos militantes previos.

Palabras clave: Milcíades Peña - intelectuales - trotskismo - izquierda

Abstract: Milciades Peña was one of the most important intellectuals of the Argentine left in the twentieth century. Proposed a marxist view original and critical on the national past, the country's socio-economic structure, the ruling class and the peronism. In this article, based on the analysis of primary sources, examines issues little explored: the way in which sentence was inserted into one of the trends in argentine trotskyism; features theoretical, political, organizational and program of the stream; and the incidence that this experience had militant in the intellectual training of Peña. The proposed hypothesis is that, while the theoretical production of Peña later was becoming an extraordinary lucidity and creative autonomy, can hardly be understood without their previous contexts militants.

Keywords: Milcíades Peña - intellectuals - trotskyism - left

Recepción: 2 de julio de 2013. Aprobación: 30 de agosto de 2013 